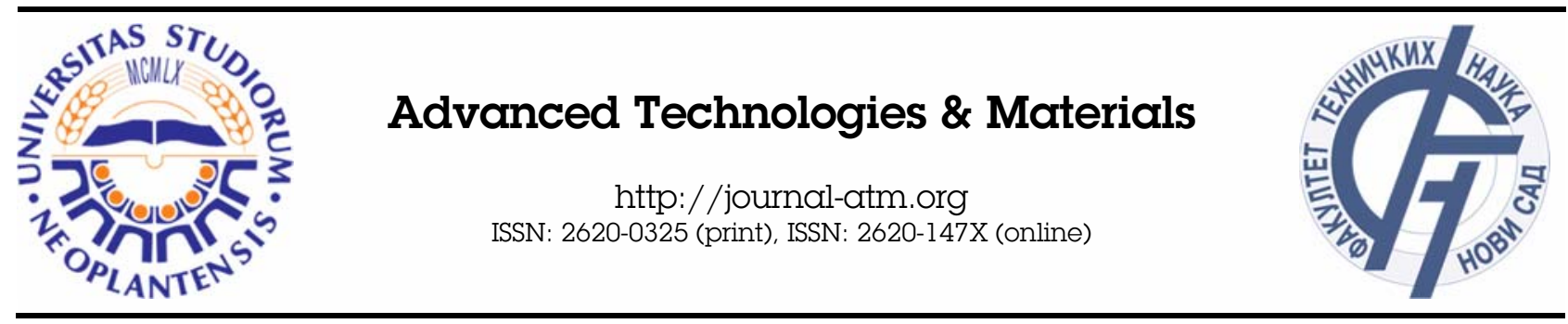

Original article

\title{
Multi response parameters optimization of ZA-27 nanocomposites
}

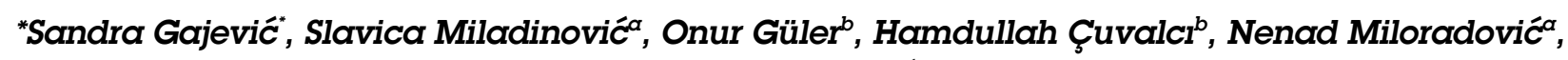 \\ Blaža Stojanovića
}

\author{
${ }^{a}$ Faculty of Engineering University of Kragujevac: Sestre Janjic 6, 34000 Kragujevac, Serbia \\ ${ }^{b}$ Karadeniz Technical University, Metallurgical and Materials Engineering: 61080 Trabzon, Turkey
}

\begin{abstract}
In this study, Taguchi-Grey relational analysis was used to investigate and optimize wear parameters such as sliding speed, reinforcement of $\mathrm{Gr}$ and reinforcement of $\mathrm{Al}_{2} \mathrm{O}_{3}$, and their effect on dry sliding wear performance of ZA-27 nanocomposites. Nanocomposites were synthesized via hot pressing process with pre-processing mechanical milling. Sixteen experimental tests were performed based on design of experiments which was created with the help of Taguchi L16 orthogonal array. Grey relational analysis (GRA) was applied for determination of optimal combination of parameters in order to improve tribological characteristics. Optimal combination of factors, obtained with Taguchi Grey relational analysis was sliding speed of $100 \mathrm{rpm}$, reinforcement content of $1 \mathrm{vol} . \% \mathrm{Gr}$ and reinforcement content of $4 \mathrm{vol} . \% \mathrm{Al}_{2} \mathrm{O}_{3}$. Validation of results was done by using Artificial Neural Network (ANN). Developed model had overall regression coefficient 0.99836, and output values showed good correlation with experimental results. Based on this research, it can be observed that nanocomposites with reinforcement of $\mathrm{Gr}$ and $\mathrm{Al}_{2} \mathrm{O}_{3}$ can be potentially employed in many industries as a good substitute for the base alloy. In addition, as a result of the analysis of the worn surfaces, it was determined that with the increase of the $\mathrm{Al}_{2} \mathrm{O}_{3} \mathrm{ratio}_{\text {, the hard }}$ $\mathrm{Al}_{2} \mathrm{O}_{3}$ nanoparticles turned the dominant wear mechanism into abrasive. Also, it was determined that the Gr nanoparticles appeared on the abrasive wear lines.
\end{abstract}

Key words: Hybrid nanocomposite, ZA27 alloy, wear loss, coefficient of friction, ANOVA, GRA, ANN;

\section{INIRODUCTION}

Composites have a great influence in the development of today's industry, due to their different tremendous properties. Nanocomposites are combination of nanoreinforcement and base material. Nanoreinforcements can be nanopraticles, nanotubes, nanowhiskers, nanofibers and nanoplates. Mostly used nanoreinforcements are nanoparticles which have a very small size. As base materials in metal matrix nanocomposites (MMNC) widely used are aluminium, zinc, magnesium, titanium and their alloys). Zinc aluminium alloy (ZA) are characterized by good combination of physical, mechanical and technological properties and low manufacturing costs. Alloy ZA27 has the highest tensile strength and wear properties compared to other ZA alloys, which makes this alloy a good material for a replacement of bronze bearings $[1,2,3]$.

Experimental research of many authors is based on improvement of tribological and mechanical properties of
ZA alloys by adding nanoreinforcements like $\mathrm{SiC}$, Gr, $\mathrm{Al}_{2} \mathrm{O}_{3}, \mathrm{ZrO}_{2}$ and others. In addition to the above these nanocomposites are characterised by easy machinability and low manufacturing costs. Vencl et al. have conducted research of structural, mechanical and tribological properties of nanocomposites using $\mathrm{Zn} 25 \mathrm{Al} 3 \mathrm{Si}$ and $\mathrm{Zn} 25 \mathrm{Al} 3 \mathrm{Si} 0.03 \mathrm{Sr}$ alloys as the matrices and nanoparticles of 1 wt. $\% \mathrm{Al}_{2} \mathrm{O}_{3}$ as the reinforcement. Nanocomposites were fabricated by compocasting process [4]. After the extensive testing they concluded that there was improvement in mechanical and tribological properties of nanocomposites compared to the matrix alloy. Improvement in mechanical properties of nanocomposites with the base of ZA27 fabricated by compocasting process have observed Bobic et al. They used different ceramic reinforcements more precisely $\mathrm{Al}_{2} \mathrm{O}_{3}(20-30 \mathrm{~nm}$ and 100 $\mathrm{nm})$, and $\mathrm{SiC}(50 \mathrm{~nm})$ nanoparticles [5]. Hybrid nanocomposites with ZA27 base and $\mathrm{B}_{4} \mathrm{C}$ and $\mathrm{Gr}$ reinforcements were researched by Güler et al [6]. In process of fabrication the time of mechanicall milling was

Corresponding author's.e-mail: sandrav@kg.ac.rs

Published by the University of Novi Sad, Faculty of Technical Sciences, Novi Sad, Serbia.

This is an open access article distributed under the CC BY-NC-ND 4.0 terms and conditions 
varied and then it was followed by hot-pressing technique. Improvement in properties of these nanocomposites was observed. Application of optimization methods in all stages of research is constantly increasing. Many researchers have successfully applied various optimization techniques like Taguchi method, Response Surface Method (RSM), Artificial Neural Network (ANN), Grey Relational Analysis (GRA), Genetic Algorithm (GA), and many others, in the aim for optimization of the process parameters.

Taguchi analysis was applied by Shivakumar et al. in order to reduce wear volume loss of $\mathrm{ZA} 27 / \mathrm{Al}_{2} \mathrm{O}_{3}$ nanocomposite [7]. They used different weight percentage of $\mathrm{Al}_{2} \mathrm{O}_{3}$ (1, 3 and $5 \%$ ) in stir casting followed by squeeze casting technique for fabrication of composites. Tribological test were done in dry conditions and the load, sliding speed and sliding distance were varied. With ANOVA analysis it was determined that the highest influence on wear loss has reinforcement content with $77.3 \%$ and determined optimal reinforcement content was 5 wt. $\%$ of $\mathrm{Al}_{2} \mathrm{O}_{3}$.

Prabhu et. al. [8] applied GRA for multi-objective optimization of the considered parameters in order to minimize surface roughness and contact surface temperature. Input parameters of spindle speed, feed and depth of cut are used and responses of surface roughness for pure copper, copper with $3 \mathrm{~g}$ CNT and copper with $3 \mathrm{~g}$ graphene nanocomposite are determined. Their results show that by applying GRA analysis reliable optimization of machining parameters of both surface roughness and contact temperature is possible.

A very successful application of the Taguchi method and GRA has been reported, also, by Hussain et al. [9] in their investigation of the effect of powder metallurgy processing parameters on multi-responses: mass density and hardness of $\mathrm{Al}_{2} \mathrm{O}_{3} / \mathrm{Cu}$ composite. Using GRA analysis, they determined the optimal combination of parameters and ANOVA analysis established the percentage of influence of each observed input parameter.

Varol et al. [10] studied the effect of matrix size $(28,60$, 100 and $162 \mu \mathrm{m}), \mathrm{SiC}$ content (1, 3 and $5 \mathrm{wt} . \%)$ and milling time $(1,1.5$ and $2 \mathrm{~h}$ ) on the density and hardness of AA2024-SiC nanocomposites by application of ANN. Nanocomposites fabricated by powder metallurgy. They reported that the predicted values are closer to the experimental results which show that developed model has a high reliability and potential to be used for the prediction of density and hardness of AA2024-SiC nanocomposites. The success of the ANN model has been demonstrated by Tyagi et al. [11]. They combined ANN with RSM, by observing the tool rotational speed, applied load and sliding distance in analysis of wear behavior of the composites. By comparing two developed models it was found that prediction of ANN model is more precise than the RSM model.

In this paper tribological properties of ZA27 based MMNC reinforced with ceramic and soft nanoparticles were investigated. Taguchi design of experiment was used to investigate dry sliding wear behaviour of the ZA27/ $\mathrm{Al}_{2} \mathrm{O}_{3} / \mathrm{Gr}$ nanocomposite. Purpose of this paper is to examine the influence of the factors on the tribological characteristics on the ZA27 based MMNC reinforced with ceramic and soft nanoparticles in order to determine the wear loss and coefficient of friction one at the time. The motivation for the presented investigation is to perform multi response optimization by converting it to a single relational grade and again do the influence of the factors considering both outputs simultaneously. GRA has been employed in numerous disciplines to solve multiple response problems. After the analyzes performed using ANN analysis, the tribological characteristics are predicted.

\section{METHODS AND MATERIALS}

\subsection{Optimization methods}

Taguchi method for design of experiments aims to examine how different factors affect the mean values and variations of process parameters that determine how well a process functions. The proposed experimental design involves the use of orthogonal matrices to organize the factors that affect the process and the levels at which they should change. The application of orthogonal arrays enables the collection of the necessary data to determine which factors have the greatest impact on quality characteristics with a minimum number of experiments, thus saving time and resources. Analysis of the variable based on the collected data from Taguchi design of experiments can be used to select a new parameter value to optimize performance characteristics. A statistical analysis of output for the given combination of input parameters, called Signal-to-Noise $(\mathrm{S} / \mathrm{N})$ ratio analysis, is used in Taguchi design. Three standard categories of $\mathrm{S} / \mathrm{N}$ ratios are: "higher the better", " smaller the better" and "nominal the better". Depending of desired output values, $\mathrm{S} / \mathrm{N}$ ratios are calculated from one of the standard categories and for determination of the optimum condition of each response, maximum values of $\mathrm{S} / \mathrm{N}$ ratios are used [12], [13]. The orthogonal arrays are designed such that in each level of any process parameter, every other levels of the factor appear similar number of times to give a balanced design.

Taguchi's experimental method is adequate for optimization of single response characteristic process parameters. When there are two or more responses Taguchi method is combined with GRA. GRA is a technique used to solve multiple outputs that have complicated relationships between them. The objective of applying GRA is to explore the relationships among the inputs to identify the dynamic of characteristics in the process and to determine their relative influences [9], [8].

ANNs are mathematical models based on the human brain. Neural networks, as well as human brain, consist of interconnected units called neurons. Networks are trained and not programmed, data based on which they are trained comes to the input layer, and then they are transferred to hidden layer after which they go to output layer providing the prediction data [14]. Number of neurons in input and output layer depends on the number of observed input and output parameters, while number of neurons in hidden layer depends of the experience of person modeling the network. Mostly used networks are feedforward 
backpropagation neural networks with only three layersinput, hidden and output layer. The Levenberg-Marquardt (TRAINLM) is network training function used in the formation and training of the network because it is mainly recommended [11]. In the hidden layer, neurons work based on the Log-Sigmoid transfer function or Tangent Sigmoid function (logsig or tansig) and in the output layer based on the Linear transfer function (purelin). After training of the network plots for regression coefficients (training, test, validation and overall) are obtained, as well as performance and training state plots.

\subsection{Materials}

The average particle size of nano $\mathrm{Gr}$ and nano $\mathrm{Al}_{2} \mathrm{O}_{3}$ particles used in the fabrication of hybrid nanocomposites with ZA27 matrix is approximately $50 \mathrm{~nm}$ and $100 \mathrm{~nm}$, respectively. While the mechanical milling method was used to embed the reinforcement nano particles into the matrix and mix with each other, the hot pressing method was used in the production of final hybrid nanocomposites. A detailed workflow chart about the study followed in material production can be seen in previous studies $[15,16]$.

\subsection{Design of experiments}

In order to obtain the optimum combination for the nanocomposite with the lowest coefficient of friction $(\mathrm{CoF})$ and wear loss (WL), three four-level factors were considered. These factors are: sliding speed $(100,150,200$ and $250 \mathrm{rpm})$, content of $\mathrm{Gr}(1,2,3$ and 4 vol.\%) and content of $\mathrm{Al}_{2} \mathrm{O}_{3}(1,2,3$ and 4 vol.\%). Factors that have an influence on WL and $\mathrm{CoF}$ are given in table 1 . With $\mathrm{A}$ is marked sliding speed, $\mathrm{B}$ is content of $\mathrm{Gr}$, and $\mathrm{C}$ is content of $\mathrm{Al}_{2} \mathrm{O}_{3}$. All experiments were done for constant load of $10 \mathrm{~N}$.

Table 1 - Levels for various control factors.

\begin{tabular}{lccccc}
\hline Control & Units & \multicolumn{4}{c}{ Levels } \\
\cline { 3 - 6 } factors & & I & II & III & IV \\
\hline $\mathrm{A}$ & $\mathrm{rpm}$ & 100 & 150 & 200 & 250 \\
$\mathrm{~B}$ & $\mathrm{vol. \%}$ & 1 & 2 & 3 & 4 \\
$\mathrm{C}$ & $\mathrm{vol.} \%$ & 1 & 2 & 3 & 4 \\
\hline
\end{tabular}

For experimental design was used the orthogonal array L16, which was obtained by applying the Taguchi mixed-level design. Statistical analysis of wear loss and CoF of ZA27 nanocomposites are performed by $\mathrm{S} / \mathrm{N}$ ratio, ANOVA, GRA and ANN.

In this paper $\mathrm{S} / \mathrm{N}$ ratio analyses of wear loss and $\mathrm{CoF}$ by using smaller the better quality characteristic as responses have to be minimized [12]. The equation for calculating the $\mathrm{S} / \mathrm{N}$ ratio for Taguchi characteristic "smaller the better" can be found in [13]. Experimental results are converted with $\mathrm{S} / \mathrm{N}$ ratio in order to perform a characteristic analysis.

\section{RESULTS AND DISCUSSION}

After conducting laboratory experiments, Experimental results for the $\mathrm{WL}$ and $\mathrm{CoF}$ are obtained by using an orthogonal array for different factor combinations, and they are given in Table 2. Analysis of the results was performed using Minitab 19 to determine the optimum combinations of the reinforcement content that will yield optimal values of the responses. The values of the $\mathrm{S} / \mathrm{N}$ ratio of a WL and CoF are also given in table 2 .

Table 2 - Experimental results and results of $S / N$ analysis.

\begin{tabular}{lccccccc}
\hline $\begin{array}{l}\text { No. } \\
\text { exp. }\end{array}$ & $\boldsymbol{A}$ & $\boldsymbol{B}$ & $\boldsymbol{C}$ & $\begin{array}{c}\boldsymbol{W L} \\
(\mathbf{m g})\end{array}$ & $\boldsymbol{C o F}$ & $\begin{array}{c}\text { S/N for } \\
\boldsymbol{W L}\end{array}$ & $\begin{array}{c}\text { S/N for } \\
\mathbf{C o F}\end{array}$ \\
\hline 1 & 100 & 1 & 1 & 9.8 & 0.343 & -19.825 & 9.288 \\
2 & 100 & 2 & 2 & 9.0 & 0.311 & -19.085 & 10.143 \\
3 & 100 & 3 & 3 & 10.0 & 0.336 & -20.000 & 9.487 \\
4 & 100 & 4 & 4 & 6.2 & 0.236 & -15.848 & 12.561 \\
5 & 150 & 1 & 2 & 9.1 & 0.323 & -19.181 & 9.823 \\
6 & 150 & 2 & 1 & 17.1 & 0.392 & -24.660 & 8.138 \\
7 & 150 & 3 & 4 & 9.3 & 0.306 & -19.370 & 10.301 \\
8 & 150 & 4 & 3 & 9.2 & 0.257 & -19.276 & 11.807 \\
9 & 200 & 1 & 3 & 6.0 & 0.23 & -15.563 & 12.754 \\
10 & 200 & 2 & 4 & 9.2 & 0.257 & -19.276 & 11.806 \\
11 & 200 & 3 & 1 & 21.4 & 0.388 & -26.608 & 8.226 \\
12 & 200 & 4 & 2 & 25.6 & 0.372 & -28.165 & 8.600 \\
13 & 250 & 1 & 4 & 4.5 & 0.202 & -13.064 & 13.897 \\
14 & 250 & 2 & 3 & 10.0 & 0.296 & -20.000 & 10.567 \\
15 & 250 & 3 & 2 & 16.9 & 0.359 & -24.558 & 8.909 \\
16 & 250 & 4 & 1 & 31.7 & 0.411 & -30.021 & 7.725 \\
\hline
\end{tabular}

\subsection{Analysis of the results}

\subsubsection{S/N ratios}

Analysis of the effect of each control factor on the tribological characteristics was performed with $\mathrm{S} / \mathrm{N}$ analysis. Arithmetic means of the $\mathrm{S} / \mathrm{N}$ ratio calculated for each level of considered factors in comparison with WL and $\mathrm{CoF}$, are shown in table 3 . Analysis of $\mathrm{S} / \mathrm{N}$ ratios of the experimental results determined order of factor importance (Rank).

Table 3 - Responses Table for S/N Ratios.

\begin{tabular}{lcccccc}
\hline & \multicolumn{3}{c}{ WL } & \multicolumn{3}{c}{ CoF } \\
\hline Level & $\boldsymbol{A}$ & $\boldsymbol{B}$ & $\boldsymbol{C}$ & $\boldsymbol{A}$ & $\boldsymbol{B}$ & $\boldsymbol{C}$ \\
\hline 1 & -18.69 & -16.91 & -25.28 & 10.370 & 11.440 & 8.344 \\
2 & -20.62 & -20.76 & -22.75 & 10.017 & 10.163 & 9.369 \\
3 & -22.40 & -22.63 & -18.71 & 10.346 & 9.231 & 11.154 \\
4 & -21.91 & -23.33 & -16.89 & 10.274 & 10.173 & 12.141 \\
Delta & 3.71 & 6.42 & 8.39 & 0.352 & 2.210 & 3.797 \\
Rank & 3 & 2 & 1 & 3 & 2 & 1 \\
Edelta & & 18.52 & & & 6.359 & \\
Weight & & $\mathbf{0 . 7 4}$ & & & $\mathbf{0 . 2 6}$ & \\
\hline
\end{tabular}


Based on the table 3 it can be observed that the highest influence on wear loss and $\mathrm{CoF}$ has the content of $\mathrm{Al}_{2} \mathrm{O}_{3}$ followed by content of $\mathrm{Gr}$ and sliding speed. Optimal combination of factors can be seen on the figure 1 or determined from table 2 according to the highest $\mathrm{S} / \mathrm{N}$.

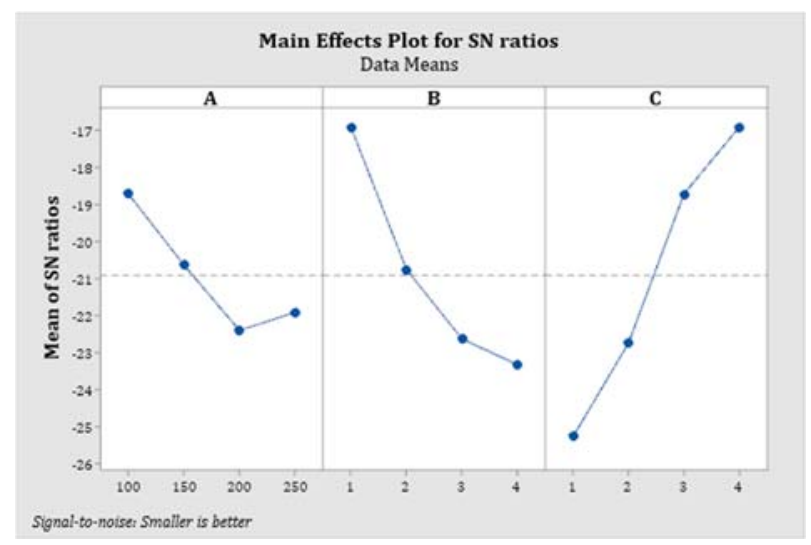

(a)

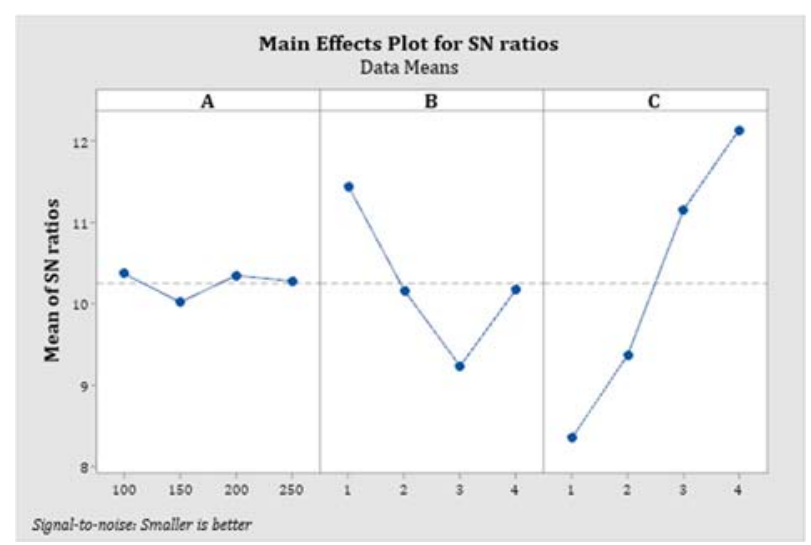

(b)

Fig. 1 Main effects plot for (a) WL; (b) CoF of nanocomposite.

The analysis of experimental results using the $\mathrm{S} / \mathrm{N}$ ratio gives the optimal values of the $\mathrm{WL}$ and $\mathrm{CoF}$, according to table 3 and figure 1 optimal factor combination for WL and CoF is A1B1C4, more precisely: sliding speed of $100 \mathrm{rpm}$, reinforcement content of 1 vol.\% Gr and reinforcement content of 4 vol. $\% \mathrm{Al}_{2} \mathrm{O}_{3}$.

\subsubsection{ANOVA analysis}

Analysis of variance (ANOVA) is a statistical method for determining the impact of various input factors and for interpreting experimental data. Degrees of freedom (DF), mean square (MS), sum of squares (SS), F and $P$ values and percent of contribution are all included in ANOVA analysis. The effect of sliding speed and reinforcement content of $\mathrm{Gr}$ and $\mathrm{Al}_{2} \mathrm{O}_{3}$ on tribological behaviour of nanocomposite was performed with a $95 \%$ confidence level.

The results of ANOVA for wear loss are given in [17] and show that the wear behaviour of nanocomposite is highly affected by $\mathrm{Al}_{2} \mathrm{O}_{3}$ reinforcement content with $52.99 \%$, followed by reinforcement content of $\mathrm{Gr}$ with $30.30 \%$ while the sliding speed has the least influence with $10.05 \%$ on the wear loss of nanocomposites. CoF of nanocomposite is, also, highly affected by $\mathrm{Al}_{2} \mathrm{O}_{3}$ reinforcement content $(69.01 \%)$, followed by reinforcement content of $\mathrm{Gr}$ $(19.37 \%)$ while sliding speed $(0.61 \%)$ has almost no influence on the $\mathrm{CoF}$ of nanocomposites.

\subsubsection{GRG analysis}

The procedure for optimization of the responses simultaneously using GRA consists of several steps. The first step in this analysis is normalization of experimental results (data preprocessing), an equation can be found in the literature [18]. The second step in the GRA is the determination of the deviation sequence, then the calculation of Grey relation coefficient (GRC) and. in the end, determination of the Grey relational grade (GRG). Equations for calculating GRG can be found in [18]. Table 3, for $\mathrm{S} / \mathrm{N}$ analysis, in the last row shows weight coefficients used in the Grey analysis for each output and using them to determine the $\mathrm{j}$-th GRG on the basis of which the ranking is performed.

GRG was calculated to determine the effects of factors on the experiment results, and was ranked from 1 to 16 , where 1 is for the best combination of factors (Table 4). In table 4 with GRC $\mathrm{CoF}$ was marked Grey coefficient for coefficient of friction while with GRC WL was marked Grey coefficient for wear loss.

Table 4-ANOVA for S/N ratios WL and COF.

\begin{tabular}{lcccccc}
\hline & $\begin{array}{c}\text { NORM. } \\
\text { WL }\end{array}$ & $\begin{array}{c}\text { NORM. } \\
\text { CoF }\end{array}$ & $\begin{array}{c}\text { GRC } \\
\text { WL }\end{array}$ & $\begin{array}{c}\text { GRC } \\
\text { CoF }\end{array}$ & GRG & RANK \\
\hline 1 & 0.805 & 0.325 & 0.720 & 0.426 & 0.643 & 10 \\
2 & 0.835 & 0.478 & 0.751 & 0.489 & 0.683 & 6 \\
3 & 0.798 & 0.359 & 0.712 & 0.438 & 0.641 & 11 \\
4 & 0.938 & 0.837 & 0.889 & 0.755 & 0.854 & 3 \\
5 & 0.831 & 0.421 & 0.747 & 0.463 & 0.673 & 8 \\
6 & 0.537 & 0.091 & 0.519 & 0.355 & 0.476 & 13 \\
7 & 0.824 & 0.502 & 0.739 & 0.501 & 0.677 & 7 \\
8 & 0.827 & 0.737 & 0.743 & 0.655 & 0.720 & 4 \\
9 & 0.945 & 0.866 & 0.901 & 0.789 & 0.872 & 2 \\
10 & 0.827 & 0.737 & 0.743 & 0.655 & 0.720 & 4 \\
11 & 0.379 & 0.110 & 0.446 & 0.360 & 0.423 & 14 \\
12 & 0.224 & 0.187 & 0.392 & 0.381 & 0.389 & 15 \\
13 & 1.000 & 1.000 & 1.000 & 1.000 & 1.000 & 1 \\
14 & 0.798 & 0.550 & 0.712 & 0.526 & 0.664 & 9 \\
15 & 0.544 & 0.249 & 0.523 & 0.400 & 0.491 & 12 \\
16 & 0.000 & 0.000 & 0.333 & 0.333 & 0.333 & 16 \\
\hline
\end{tabular}

According table 4 the best combination of factors is for experiment number 13, where sliding speed was $250 \mathrm{rpm}$, reinforcement content was $1 \mathrm{vol} \% \mathrm{Gr}$ and reinforcement content was 4 vol.\% $\mathrm{Al}_{2} \mathrm{O}_{3}$. After GRA analysis, $\mathrm{S} / \mathrm{N}$ analysis was done for GRG results. 
The optimal combination of factors can now be determined by GRG analysis and the results of the analysis are given in Table 5.

Table 5-Response table of S/N analysis for GRG.

\begin{tabular}{lccc}
\hline Level & $\boldsymbol{A}$ & $\boldsymbol{B}$ & $\boldsymbol{C}$ \\
\hline 1 & -3.095 & -2.115 & -6.820 \\
2 & -4.027 & -4.040 & -5.280 \\
3 & -4.927 & -5.223 & -2.867 \\
4 & -4.820 & -5.491 & $-\mathbf{1 . 9 0 1}$ \\
Delta & 1.832 & 3.376 & 4.919 \\
Rank & $\mathbf{3}$ & $\mathbf{2}$ & $\mathbf{1}$
\end{tabular}

The optimum level of each experiment parameter is bolded value given in Table 5 and shown in Figure 2.

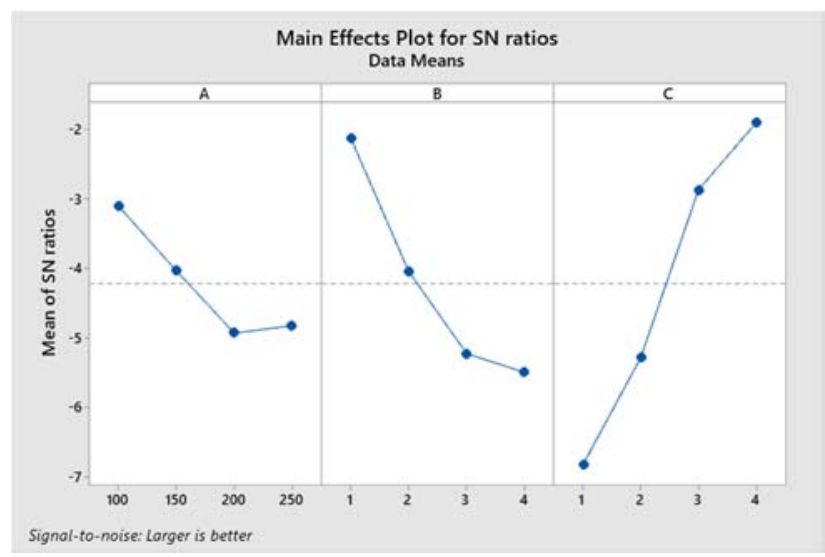

Fig. 2 Main effects plot of S/N analysis for GRG.

The optimal combination of factors for GRG is sliding speed of $100 \mathrm{rpm}$, reinforcement content of $1 \mathrm{vol} \% \mathrm{Gr}$ and reinforcement content of 4 vol.\% $\mathrm{Al}_{2} \mathrm{O}_{3}$. After the GRA analysis, the ANOVA analysis is applied to the GRG and the results of the mentioned analysis are shown in Table 6.

Table 6 - ANOVA for GRG.

\begin{tabular}{lccccccc}
\hline Source & DF & $\begin{array}{c}\text { Seq } \\
\text { SS }\end{array}$ & $\begin{array}{c}\text { Adj } \\
\text { SS }\end{array}$ & $\begin{array}{c}\text { Adj } \\
\text { MS }\end{array}$ & F & P & $\%$ \\
\hline A & 3 & 32.98 & 32.98 & 10.994 & 3.02 & 0.116 & 10.05 \\
B & 3 & 99.42 & 99.42 & 33.139 & 9.09 & 0.012 & 30.30 \\
C & 3 & 173.86 & 173.86 & 57.953 & 15.90 & 0.003 & 52.99 \\
Residual & 6 & 21.87 & 21.87 & 3.644 & & & 6.67 \\
Error & & & & & & & \\
Total & 15 & 51.01 & & & & & 100 \\
\hline
\end{tabular}

Based on the conducted ANOVA analysis, at the level of 95\% reliability, it can be established that the greatest influence on tribological characteristics (WL and CoF) has the content of $\mathrm{Al}_{2} \mathrm{O}_{3}$ with $52.99 \%$, followed by factor $\mathrm{B}$ more precisely the content of Gr with $30.30 \%$ and factor A sliding speed with $10.05 \%$. It should be noted that the percentage influence of factors on the GRG response corresponds to the range of factors obtained by $\mathrm{S} / \mathrm{N}$ analysis (Table 5).
It is possible to create 2D diagrams of dependence of GRG and the most influential factors, such diagram is shown in Figure 3.

In the previous figure, a dark green area can be observed. This area is of interest, because the minimum of WL and $\mathrm{CoF}$ is achieved for these factor values. Then the slightly lighter green color of the area on the diagram indicates that the content of $\mathrm{Gr}$ above 3 vol.\% can be combined with the content of $\mathrm{Al}_{2} \mathrm{O}_{3}$ above 2 vol.\%. to obtain mean values of $\mathrm{WL}$ and $\mathrm{CoF}$ nanocomposite. The highest wear rate occurs when using a content of $\mathrm{Gr}$ above 3.4 vol. $\%$ with an $\mathrm{Al}_{2} \mathrm{O}_{3}$ content of 1 to 2 vol. $\%$.

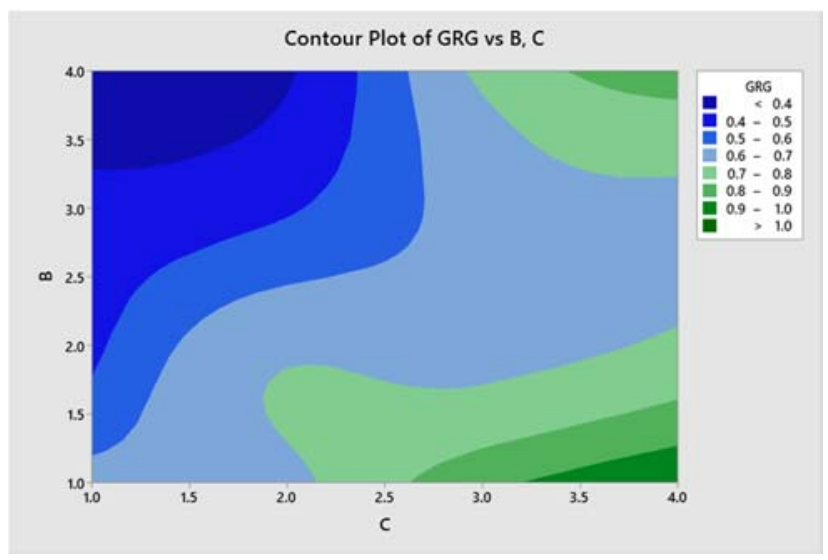

Fig. 3 Effect of factors content of $\mathrm{Gr}$ and content of $\mathrm{A}_{2} \mathrm{O}_{3}$ on $\mathrm{GRG}$.

\subsubsection{ANN analysis}

In order to verify the results obtained by the Taguchi method and Taguchi Grey method prediction is performed by training experimental data using the ANN. In this purpose neural network with 3 input factors, 15 neurons in hidden layer and 2 output values was created. The network trained with the help of the software Matlab R2016a is feed forward neural network, with LOGSIG transfer function and the TRAINLM as a training function. On figure 4 is represented plot of regression coefficient for training, validation and testing, as well as the overall regression coefficient of the trained network. Observing the values for the regression coefficients, it can be found that the coincidence of the results obtained by ANN training and experimental is very good, as indicated by the total regression coefficient of 0.99836 .

By observing regression coefficients for testing, validation, training and overall, it can be concluded that the trained network can be used for prediction of responses with high reliability.

\subsection{SEM and EDS analysis of ZA-27 nanocomposites}

Figure 5 presents SEM images of the worn surfaces obtained as a result of wear tests carried out at different sliding speeds of hybrid nanocomposites with ZA27 matrix and containing $1 \%$ vol. and $4 \%$ vol. $\mathrm{Gr}$ and $\mathrm{Al}_{2} \mathrm{O}_{3}$ nanoparticles, respectively. By examining the wear surfaces of nanocomposites in this content, the dominant 
wear mechanisms occurring in nanocomposites with the lowest wear loss values were investigated.

As can be understood from the figure 5, fewer wear lines were formed on the worn surface obtained at the sliding speed of $150 \mathrm{rpm}$ than at $100 \mathrm{rpm}$ (see figure 5a) and the worn surface transferred into the smoother worn surface. As a result of the wear experiment applied at a sliding speed of $200 \mathrm{rpm}$ (see figure 5b), the surface continued to become flatter (see figure 5c). As mentioned before, the wear losses decreased by increasing the sliding speed up to $200 \mathrm{rpm}$. This is supported by fewer wear lines and a flatter surface on the wear surface. It was clearly seen that the addition of $4 \% \mathrm{vol}$. hard $\mathrm{Al}_{2} \mathrm{O}_{3}$ nanoparticles caused the dominant wear mechanism of the abrasive wear. The reduction in wear losses and the smoother surface can be attributed to the decrease in the specific contact area between the abrasive disc and the sample during wear tests when the sliding speed is increased up to $200 \mathrm{rpm}$ with narrower abrasive wear lines. On the other hand, it was observed that the wear lines started to increase and widen as the sliding speed increased further and reached $250 \mathrm{rpm}$ as seen in figure $5 \mathrm{~d}$. The increase in the sliding speed and the temperature increases between the abrasive disc and the sample caused tears at the wear line ends of the materials.
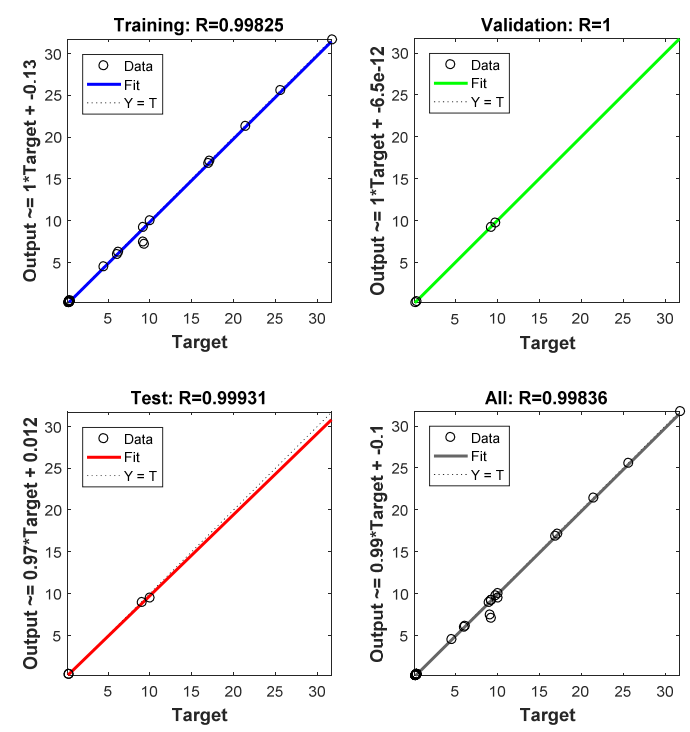

Fig. $4 A N N$ regression plot for $W L$ and $C O F$

Although tears occur with the effect of temperature, it is revealed by the intensity of the wear lines that the dominant wear mechanism is protected as abrasive. In addition, pitting occurred in some areas on the wear surfaces of the samples where the sliding speed was applied as $250 \mathrm{rpm}$ (figure 5d). The fact that some parts of the ductile ZA27 matrix material adhered to the abrasive disc by the effect of temperature are detached from the worn surface with the continuation of sliding can be shown as the cause of this situation.

The mapping analysis of the worn surface resulting from the wear tests of ZA27-1\%vol.Gr-4\%vol. $\mathrm{Al}_{2} \mathrm{O}_{3}$ hybrid nanocomposites under $250 \mathrm{rpm}$ shear speed is given in figure 6 . As can be seen, oxide formation has occurred in the edge regions of the formed grooves. In addition to the oxide from $\mathrm{Al}_{2} \mathrm{O}_{3}$, the increase in temperature caused by the increase in sliding speed has caused to oxidize of the matrix material. In addition, the presence of the carbon element was observed in the groove regions. This shows that graphite, which is a carbon product, comes to the surface in damaged and pitting areas due to its lubricating and soft structure. This implication supports that the effect of $\mathrm{Al}_{2} \mathrm{O}_{3}$ nanoparticles additive on wear performance is bigger than that of $\mathrm{Gr}$ nanoparticles. In addition, it is seen that the regions where iron $(\mathrm{Fe})$ element were detected at the edges of the grooves. Therefore, it was determined that the increase in the sliding speed causes adhesion of matrix material on the abrasive disc followed by the transferring of Fe from the abrasive disc surface to the worn surface of sample surface.

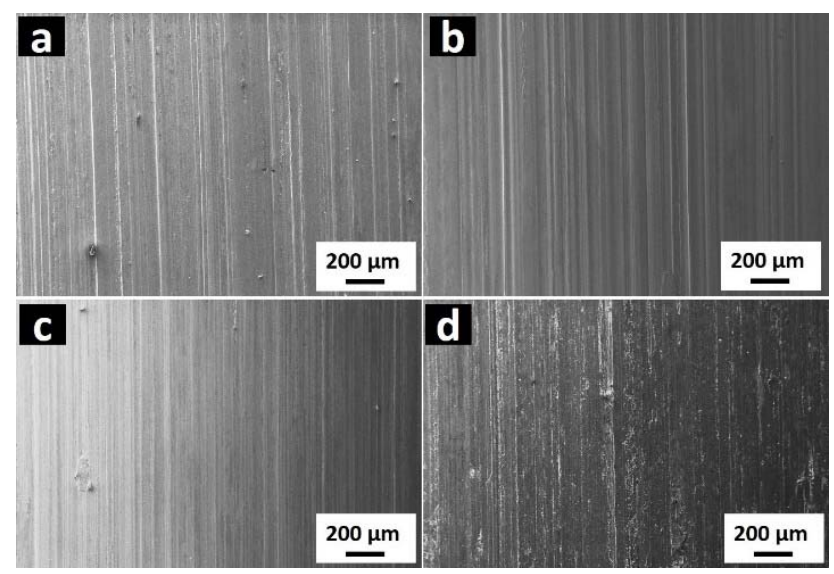

Fig. 5 Worn surfaces of ZA27 hybrid nanocomposites reinforced 1 vol.\% Gr and 4 vol.\% Al2O3 under the sliding speed of (a) 100; (b) 150; (c) 200; (d) $250 \mathrm{rpm}$.

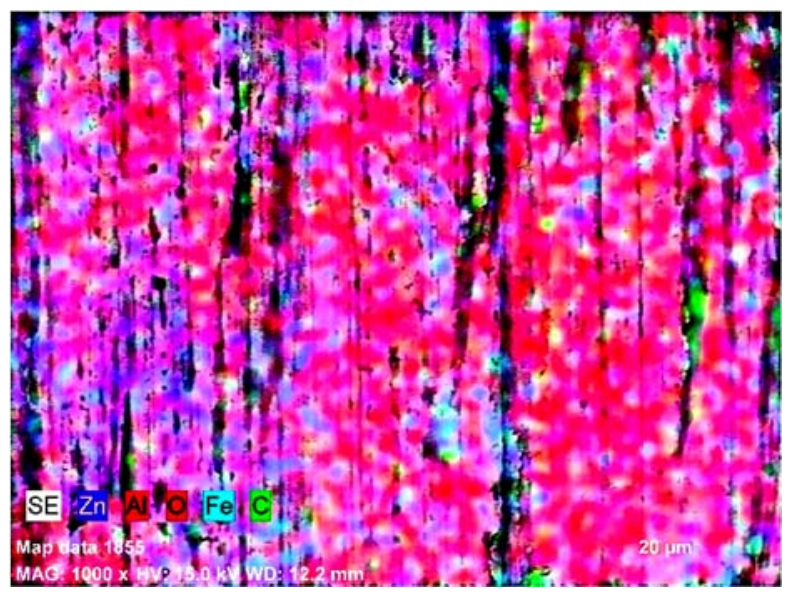

Fig. 6 The mapping images for the worn surface of ZA27 composites with 1 vol. \% Gr and 4 vol.\% $\mathrm{Al}_{2} \mathrm{O}_{3}$ under the sliding speed of $250 \mathrm{rpm}$

\section{CONCLUSIONS}

The application of Taguchi Grey method can assist in obtaining of the optimal combination of the control factors that have influence on dry sliding wear performance of ZA27 nanocomposites with reduced time and cost of the 
experiment. This study has presented an experimental investigation of WL and $\mathrm{CoF}$ of hybrid metal matrix nanocomposite. Based on ANOVA, GRG and ANN the following conclusions can be made:

- The most influential factor on WL is reinforcement of $\mathrm{Al}_{2} \mathrm{O}_{3}$, followed by reinforcement of $\mathrm{Gr}$ and sliding speed with the least percent of influence. In analysis of $\mathrm{CoF}$ the most influential factor is reinforcement of $\mathrm{Al}_{2} \mathrm{O}_{3}$, followed by reinforcement of $\mathrm{Gr}$ and with the least influence is sliding speed.

- Based on the results of multi-response optimization approach, the optimized multi response optimization with the help of GRG analysis confirmed already stated influences as the Taguchi analysis of individual outputs. Optimal combination based on GRA analysis was obtained in limits of experiment and it was for sliding speed of $250 \mathrm{rpm}$, reinforcement content of 1 vol. $\% \quad \mathrm{Gr}$ and reinforcement content of 4 vol. $\% \mathrm{Al}_{2} \mathrm{O}_{3}$.

- $\mathrm{S} / \mathrm{N}$ analysis of multi-response optimization gave the same results as $\mathrm{S} / \mathrm{N}$ analysis of each response individually, and the lowest WR and CoF was for sliding speed of $100 \mathrm{rpm}$, reinforcement content of 1 vol.\% Gr and reinforcement content of 4 vol.\% $\mathrm{Al}_{2} \mathrm{O}_{3}$

- ANOVA analysis for GRG was determined that influence of content of reinforcement of $\mathrm{Al}_{2} \mathrm{O}_{3}$ iznosi $52.99 \%$, followed by reinforcement of $\mathrm{Gr}$ with influence of $30.30 \%$ and sliding speed with $10.05 \%$.

- By observing the achieved results, it can be concluded that ANN can be successfully used to predict the tribological characteristics of hybrid nanocomposites with ZA27 base.

- Based on worn surfaces of hybrid ZA27 nanocomposite it can be seen that dominant mechanism is abrasion.

- By applying the optimization method, better results are achieved with reduced time and cost of the experiment.

- When the worn surfaces of nano $\mathrm{Gr}$ and nano $\mathrm{Al}_{2} \mathrm{O}_{3}$ reinforced ZA27 based hybrid nano composites were examined, it was found that the dominant wear mechanism was abrasive.

- When the $\mathrm{Al}_{2} \mathrm{O}_{3}$ additive ratio was $4 \%$ vol., the hard $\mathrm{Al}_{2} \mathrm{O}_{3}$ particles caused the transfer of iron $(\mathrm{Fe})$ element from the abrasive disc to the worn sample surface.

\section{ACKNOMEDGEMENTS}

This paper presents the results obtained during research within the framework of the project TR 35021, supported by the Ministry of Education, Science and Technological Development of the Republic of Serbia. In addition, the authors would like to thank TÜBİTAK (The Scientific and Technological Research Council of Turkey) for the support in the carrying out of this study with project number 213M276.

\section{REFERENCES}

[1] Bobić, B., Bajat, J., Bobić, I., \& Jegdić, B. (2016). Corrosion influence on surface appearance and microstructure of compo cast $\mathrm{ZA} 27 / \mathrm{SiCp}$ composites in sodium chloride solution. Transactions of Nonferrous Metals Society of China, 26(6), 15121521.

[2] Shivakumar, N., Vasu, V., \& Narasaiah, N. (2017). Processing and dry sliding wear behavior of $\mathrm{Al} 2 \mathrm{O} 3$ nanoparticles reinforced ZA-27 composites. Materials Today: Proceedings, 4(2), 4006-4012.

[3] Miloradović, N., Vujanac, R., Stojanović, B., \& Pavlović, A. (2021). Dry sliding wear behaviour of ZA27/SiC/Gr hybrid composites with Taguchi optimization. Composite Structures, 264, 113658.

[4] Vencl, A., Bobić, B., Vučetić, F., Svoboda, P., Popović, V., \& Bobić, I. (2018). Effect of Al2O3 nanoparticles and strontium addition on structural, mechanical and tribological properties of $\mathrm{Zn} 25 \mathrm{Al} 3 \mathrm{Si}$ alloy. Journal of the Brazilian Society of Mechanical Sciences and Engineering, 40(11), 1-13.

[5] Bobić, B., Vencl, A., Ružić, J., Bobić, I., \&amp; Damnjanović, Z. (2019). Microstructural and basic mechanical characteristics of ZA27 alloy-based nanocomposites synthesized by mechanical milling and compocasting. Journal of Composite Materials, 53(15), 2033-2046.

[6] Güler, O., Çelebı, M., Dalmış, R., Çanakçi, A., \&Çuvalci, H. (2020). Novel ZA27/B4C/Graphite Hybrid Nanocomposite-Bearing Materials with Enhanced Wear and Corrosion Resistance. Metallurgical and Materials Transactions A, 51(9), 4632-4646.

[7] Shivakumar, N., Vasu, V., \&amp; Narasaiah, N. (2015). Synthesis and characterization of nano-sized $\mathrm{Al} 2 \mathrm{O} 3$ particle reinforced ZA-27 metal matrix composites. Procedia Materials Science, 10, 159-167.

[8] Prabhu, S., Ambigai, R., \& Vinayagam, B. K. (2021). Thermal and surface analysis of copper-CNT and copper-graphene-based composite using TaguchiGrey relational analysis. Australian Journal of Mechanical Engineering, 19(1), 95-106.

[9] Hussain, M. Z., Khan, S., \& Sarmah, P. (2020). Optimization of powder metallurgy processing parameters of $\mathrm{Al}_{2} \mathrm{O}_{3} / \mathrm{Cu}$ composite through Taguchi method with Grey relational analysis. Journal of King Saud University-Engineering Sciences, 32(4), 274286.

[10] Varol, T., Canakci, A., \& Ozsahin, S. (2018). Prediction of effect of reinforcement content, flake size and flake time on the density and hardness of flake AA2024-SiC nanocomposites using neural networks. Journal of Alloys and Compounds, 739, 1005-1014.

[11] Tyagi, L., Butola, R., Kem, L., \& Singari, R. M. (2021). Comparative analysis of response surface methodology and artificial neural network on the wear 
properties of surface composite fabricated by friction stir processing. Journal of Bio-and Tribo-Corrosion, 7(2), 1-14.

[12] Stojanovic, B., Blagojevic, J., Babic, M., Velickovic, S., \& Miladinovic, S. (2017). Optimization of hybrid aluminum composites wear using Taguchi method and artificial neural network. Industrial lubrication and tribology, 69(6), 1005-1015.

[13] Veličković, S., Stojanović, B., Babić, M., \& Bobić, I. (2017). Optimization of tribological properties of aluminum hybrid composites using Taguchi design. Journal of composite materials, 51(17), 2505-2515.

[14]Demirbay, B., Kara, D. B., \& Uğur, Ş. (2020). A Bayesian regularized feed-forward neural network model for conductivity prediction of PS/MWCNT nanocomposite film coatings. Applied Soft Computing, 96, 106632.

[15] Güler, O., Çuvalcı, H., Gökdağ, M., Çanakçi, A., \& Çelebi, M. (2018). Tribological behavior of ZA27/A12O3/graphite hybrid nanocomposites. Particulate Science and Technology, 36(7), 899-907.
[16] Güler, O., Cuvalci, H., Canakci, A., \& Celebi, M. Ü. S. L. İ. M. (2017). The effect of nano graphite particle content on the wear behaviour of ZA27 based hybrid composites. Advanced Composites Letters, 26(2), 3036.

[17] Gajević, S., Miladinović, S., Güler, O., Çuvalcı, H., Miloradović, N., Stojanović, B. (2021). Optimization of hybrid ZA 27 nanocomposites using ANOVA and ANN analysis. $15^{\text {th }}$ International Conference on accomplishments in Mechanical and Industrial Engineering DEMI 2021, Banja Luka, 28-29 May 2021, 357-362, ISBN 978-99938-39-92-7.

[18] Güler, O., Gajević, S., Miladinović, S., Çuvalcı, H., Stojanović, B. (2020). Optimization of zinc-based hybrid nanocomposites using Taguchi grey relation analysis, $8^{\text {th }}$ International Congress Motor Vehicles \& Motors 2020, Kragujevac, October 8th - 9th, 139-147, ISBN 978-86-6335-074-8. 